\title{
A standard analysis of Egyptian foreign trade structure for wheat
}

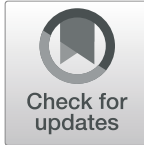

Yehia Mohamed Metwally Khalil ${ }^{1 *}$, Salah Said Abd El-Ghani² and Tamer Gamal Ibrahim Mansour ${ }^{1 *}$

\begin{abstract}
Background: Wheat is one of the most important food and strategic crops because it is the main food for most Egyptian people; the research aimed to analyze the structure of the Egyptian foreign trade for wheat by determining the most important economic factors affecting the production, consumption, and imports of wheat. By building a standard model for analyzing the foreign wheat trade market in order to narrow the gap between production and consumption so as not to negatively affect the development rates in Egypt and to alleviate the deficit of the Egyptian trade balance, the research was based on descriptive and quantitative analysis using various measures such as relative importance and averages, simple regression analysis, and Simultaneous Equation System.

Results: There is a positive correlation between the quantity of wheat consumed as a dependent variable and the quantity of imports, local production, real national income, and the population as independent variables. For example, the increase in wheat imports by 1 million tons led to an increase in the quantity consumed by 0.243 million tons; the import equation estimates that the decrease in domestic consumption of wheat by 1 million tons, the import price of wheat by one dollar, and the quantity of wheat stock by 1 million tons each lead to an increase in the quantity of imports of wheat at a rate of $0.97,0.002$, and 0.156 million tons, respectively, while the increase in real national income by 1 billion pounds increases the quantity of imports by about 0.005 million tons.

Conclusions: The study concluded that while the factors affecting Egyptian imports of wheat remain the same, the probability of an increase in the Egyptian import bill increases year after year with a consequent increase in the deficit of the Egyptian trade balance, as well as the agricultural trade balance.
\end{abstract}

Keywords: Standard analysis, Foreign trade, Wheat

\section{Background}

Wheat is one of the most important food and strategic crops because it is the main food for most people because it contains a high percentage of carbohydrate of about $75 \%$ and many vitamins and minerals. Wheat grains contain the necessary nutrients for the individual, especially protein and energy. It is important to study the factors affecting the production, consumption, and imports in order to narrow the gap between production and consumption so as not to negatively affect the rates of development in Egypt, and alleviate the deficit of the Egyptian trade balance; the average consumption was 16.6 million tons, while the production was estimated at 9.3 million tons. The wheat gap

\footnotetext{
*Correspondence: dryehia1951@yahoo.com; Tamer_baz@yahoo.com 'Department of Agricultural Economics, Division of Agricultural and Biological Research, National Research Center, El Buhouth St., Dokki, Giza 12622, Egypt

Full list of author information is available at the end of the article
}

is estimated at 7.3 million tons, and wheat and flour subsidies are estimated at 13.7 billion Egyptian pounds during the period 2012-2016 (Ministry of Agriculture publications, different years) (Ministry of Agriculture and Land Reclamation, Economic Affairs Sector, Agricultural Economics Bulletin, different years n.d.).

\section{Research problem}

Egypt is facing a population increase of about 2.5 million people annually, and despite the increase in wheat production (Central Agency for Public Mobilization and Statistics, Statistical Yearbook, different years n.d.), the corresponding increase in consumption is increasing at a higher rate, leading to an increase in Egyptian imports of wheat, which is a burden on the Egyptian agricultural trade balance. 


\section{Purpose of the study}

The research aims to analyze the structure of the Egyptian foreign trade for wheat by determining the most important economic factors affecting the production, consumption, and imports of wheat through building a standard model for analyzing the foreign wheat trade market.

\section{Research methodology and data sources}

The research was based on descriptive and quantitative analysis in the design of a standard model to analyze the structure of Egyptian imports of wheat, using various measures such as relative importance and averages, simple regression analysis, and Simultaneous Equation System (Abdelkader 2000).

The research was based mainly on statistical data published and unpublished from several sources such as the Ministry of Agriculture and the Central Agency for Public Mobilization and Statistics.

\section{Results}

According to Table 1, it was found that the study of consumption, production, and imports of wheat showed that each of them amounted to about 11.4, 5.9, and 5.5 million tons for the average period 1995-1999 and continued to increase until they reached about 16.6, 9.3, and 7.8 million tons for the average period 2012-2016. The average period to end was $45.4 \%, 56.5 \%$, and $40.6 \%$ for the consumption, production, and imports of wheat, respectively.

The general trend equations for consumption, production, and wheat imports show a statistically significant annual increase of $0.344,0.193$, and 0.175 million tons, respectively, which confirms the increase in consumption by a larger percentage of production. The increase represents $2.5 \%, 2.6 \%$, and $2.8 \%$ (1995-2016) of about 13.6, 7.5, and 6.2 million tons, and the coefficient of selection is about $0.85,0.90$, and 0.37 for consumption, production, and imports, respectively, as shown in Table 2.

Table 1 Imports, consumption, and production of Egyptian wheat and factors affecting the period (1995-2016)

\begin{tabular}{|c|c|c|c|c|c|c|c|c|c|c|}
\hline Year & $\begin{array}{l}\text { Imports (million } \\
\text { tons) }\end{array}$ & $\begin{array}{l}\text { Consumption } \\
\text { (million tons) }\end{array}$ & $\begin{array}{l}\text { Production } \\
\text { (million tons) }\end{array}$ & Import price & Stock & $\begin{array}{l}\text { National } \\
\text { real income }\end{array}$ & Exchange rate & Local price & Population & The support \\
\hline 1995 & 5.1 & 11.15 & 5.7 & 212 & 0.72 & 201.3 & 3.41 & 129 & 56.9 & 1.4 \\
\hline 1996 & 6 & 11.25 & 5.74 & 251 & 1.75 & 213.1 & 3.41 & 133.4 & 58.2 & 2.4 \\
\hline 1997 & 6.9 & 11.42 & 5.85 & 146 & 2.63 & 235.7 & 3.39 & 169 & 59.4 & 2 \\
\hline 1998 & 5.4 & 11.42 & 6 & 187 & 3.19 & 246.9 & 3.41 & 174 & 60.7 & 1.9 \\
\hline 1999 & 4.24 & 11.9 & 6.35 & 174 & 2.11 & 287.7 & 3.42 & 169 & 62 & 1.4 \\
\hline 2000 & 4.9 & 11.93 & 6.56 & 149 & 1.71 & 286.87 & 3.65 & 200 & 63.3 & 1.5 \\
\hline 2001 & 4.4 & 11.44 & 6.26 & 142 & 1.87 & 305.97 & 4.07 & 176 & 64.7 & 1.9 \\
\hline 2002 & 5.97 & 9.93 & 6.63 & 135 & 1.19 & 320.2 & 4.53 & 160 & 66 & 2.3 \\
\hline 2003 & 4.1 & 11.75 & 6.54 & 124 & 1.32 & 345.8 & 5.95 & 130 & 67.3 & 3 \\
\hline 2004 & 4.37 & 12.58 & 7.18 & 151 & 2.64 & 346.95 & 5.75 & 161 & 68.6 & 5.8 \\
\hline 2005 & 5.75 & 13.86 & 8.14 & 165 & 3.88 & 372.5 & 5.79 & 194 & 70 & 6.3 \\
\hline 2006 & 5.82 & 13.74 & 8.28 & 169 & 4.14 & $4 \mathrm{~s} 03.6$ & 5.75 & 197 & 71.3 & 6.3 \\
\hline 2007 & 5.91 & 13.32 & 7.34 & 267 & 4.27 & 451.4 & 5.43 & 204 & 73.6 & 8 \\
\hline 2008 & 4.07 & 13.74 & 7.98 & 194 & 4.86 & 488.8 & 5.54 & 470 & 75.2 & 15.2 \\
\hline 2009 & 4.01 & 13.32 & 8.52 & 375 & 5.61 & 531.9 & 5.62 & 322 & 76.9 & 16.5 \\
\hline 2010 & 9.73 & 15.45 & 7.17 & 302 & 5.48 & 573.3 & 5.07 & 322 & 78.7 & 12.3 \\
\hline 2011 & 9.79 & 15.31 & 8.37 & 316 & 6.7 & 615.6 & 7.09 & 360 & 80.5 & 15.3 \\
\hline 2012 & 8.21 & 16.18 & 8.8 & 336 & 4.72 & 724.4 & 6.88 & 382 & 82.3 & 10.8 \\
\hline 2013 & 7.11 & 16.92 & 9.46 & 356 & 4.41 & 771.98 & 6.1 & 403 & 84.6 & 11 \\
\hline 2014 & 8.11 & 16.75 & 9.3 & 376 & 4.37 & 790.2 & 5.97 & 424 & 86.8 & 14.8 \\
\hline 2015 & 8.4 & 17.8 & 9.4 & 337.2 & 5.8 & 743.8 & 5.8 & 410.5 & 88.95 & 15.6 \\
\hline 2016 & 8.6 & 18.2 & 9.6 & 347.8 & 6.1 & 774.1 & 8.8 & 426.4 & 90.3 & 16.5 \\
\hline Average & 6.22 & 13.67 & 7.5 & 236.9 & 3.61 & 456 & 5.21 & 259.8 & 72.1 & 7.8 \\
\hline
\end{tabular}

Source: Central Agency for Public Mobilization and Statistics, Statistical Yearbook, different years (Central agency for Public Mobilization and Statistics, Statistical Yearbook, different years n.d.). The Central Agency for Public Mobilization and Statistics, Annual Bulletin of Foreign Trade, different years (The Central agency for Public Mobilization and Statistics (CAPMAS), Annual Bulletin of Foreign Trade, different years n.d.). Ministry of Agriculture and Land Reclamation, Economic Affairs Sector, Agricultural Economics Publications, different years (Ministry of Agriculture and Land Reclamation, Economic Affairs Sector, Agricultural Economics Bulletin, different years n.d.) 
Table 2 Equations of the general trend of consumption, production, and imports of wheat during the period (1995-2016)

\begin{tabular}{llllll}
\hline & Estimated equations & $T$ & Period mean & $R^{2}$ & Annual growth rate (\%) \\
\hline Consumption & $y^{\wedge}=9.64+0.344 x$ & 11.1 & 13.6 & 0.85 & 2.5 \\
Production & $y^{\wedge}=5.28+0.193 x$ & 13.5 & 7.5 & 0.90 & 2.6 \\
Import & $y^{\wedge}=4.21+0.175 x$ & 3.49 .5 & 6.2 & 0.37 & 2.8 \\
\hline
\end{tabular}

Source: calculated from Table 1

It is clear from the current standard model (Ahmed 2017) that it is designed on the basis that changes in the production, consumption, and stocks have a direct impact on the quantity of wheat imports. The estimation of the econometric model of multiple equations is relatively more difficult than the single-equation models because it requires many stages and major steps of characterizing economic relations according to economic logic.

The differentiation between the variables of the model is according to certain criteria, the most important of which are the economic logic, the statistical significance, and the distance as far as possible from measurement problems, so that good estimates can be obtained which can be used in the prediction later.

\section{Model description}

The model consists of four structural equations:

1. The equation of the local consumption of wheat: It was assumed that the most important factors affecting the quantity of consumed wheat is the amount of wheat imports, the real local price of wheat, the amount of domestic production of wheat, population, real national income, the import price of wheat, and state of wheat and flour.

2. The equation of local production of wheat: It was assumed that the most important factors affecting the quantity produced from wheat are the amount of imports of wheat, the amount of wheat consumed, the real price of wheat, the import price of wheat, and the amount of stock of wheat.

3. Equation of imports of wheat: It was assumed that the most important factors affecting the amount of imports of wheat is the amount of wheat consumed, the amount of domestic production of wheat, the quantity of wheat stocks, real national income, the import price of wheat, the exchange rate of the Egyptian pound against the dollar, and the real domestic price of wheat.

4. Identify equation: In which quantity of consumed wheat $=$ quantity produced locally + quantity of imports + stock.

The model consists of structural equations that measure the direct effect of the independent variable on the dependent variable. The reduced equations measure the direct and indirect total effect of the variables specified on the internal variables which cannot be explained in the structural form of the model. The mathematical description of the behavioral and structural equations of the model is as follows:

- Equation of factors affecting the domestic consumption of wheat

Consumption equation

$$
\begin{aligned}
\mathrm{QCt}=\alpha & +\beta 1 \mathrm{QMOt}+\beta 2 \mathrm{QPOt}+\beta 3 \mathrm{RPOt}+\beta 4 \mathrm{RNIt} \\
& +\beta 5 \mathrm{Pt}+\beta 6 \mathrm{IPOt}+\beta 7 \mathrm{VSt}
\end{aligned}
$$

- Equation of factors affecting the domestic production of wheat

Production equation

$$
\begin{aligned}
\mathrm{QPt}=\alpha & +\beta 1 \mathrm{QIOt}+\beta 2 \mathrm{QCOt}+\beta 3 \mathrm{RPOt}+\beta 4 \mathrm{IPOt} \\
& +\beta 5 \mathrm{QVOt}
\end{aligned}
$$

- Equation of the factors affecting the Egyptian imports of wheat

Import equation

$$
\begin{aligned}
\mathrm{QIt}=\alpha & +\beta 1 \mathrm{QCOt}+\beta 2 \mathrm{QPOt}+\beta 3 \mathrm{QVOt}+\beta 4 \mathrm{RNIt} \\
& +\beta 5 \mathrm{IPOt}+\beta 6 \mathrm{EXDt}+\beta 7 \mathrm{RPOt}
\end{aligned}
$$

- The mathematical description of the identify equation is as follows:

Identify equation

$$
\mathrm{QCOt}=\mathrm{QPOt}+\mathrm{QIOt}+\mathrm{QVOt}
$$

For clarification: QCOt Quantity of wheat consumed per million tons per year 
QPOt Quantity produced of wheat per million tons per year

QIOt Quantity of wheat imports per million tons per year

QVOt Quantity of wheat stock in million tons per year RNIt Real national income billion pounds per year $t$ IPOt Wheat import price per dollar per ton per year RPOt Real local price of wheat/ton per year $t$ Pt Population per million inhabitants per year EXDt Exchange rate LE/dollar per year $t$

VSt Value of subsidy for wheat and flour in billion pounds per year

\section{Identification of behavioral equations}

The behavioral equations included in the structural form of the wheat import model were characterized by application requirements and demand requirements. It was found that non-zero determinants can be obtained for each behavioral equation in the form. The total number of internal and external variables of the proposed model $(K)$ minus the number of internal and external variables in equation $(L)$ is greater than or equal to the number of internal variables $(K L)$. Therefore, behavioral equations meet the criteria of degree and degree, which are overly defined, which means that it is possible to find a single unique solution to the structural features of the proposed model of the wheat production, consumption, and imports.

Thus, the best method of estimation in this case is the 2SLS method, which gives more efficient estimates.

The results of the estimates of the analysis model of the Egyptian imports of wheat Results of the first phase estimates of the model (structural equations)

The first stage is to estimate the consumption, production, and import functions. Table 3 shows the following.

Factors affecting the domestic consumption of wheat It was found that there is a positive correlation between the quantity of wheat consumed as a dependent variable and the quantity of imports, local production, real national income, and the population as independent variables. However, the relationship between the quantity of wheat consumption, the local production of wheat and population, and the increase in wheat imports by 1 million tons led to an increase in the quantity consumed by 0.243 million tons. It was also found that increasing the

Table 3 Estimates of structural equations of the standard model. Source: calculated from Table 1

Consumption Equation

$\mathbf{Q C O t}=3.69+0.243 \mathrm{QIOt}+\mathbf{0 . 6 8 5} \mathrm{QPOt}+0.003 \mathrm{RPOt}+0.02 \mathrm{RNIt}+$

$(0.32)$
$(2.9) *$
$(2.7) *$

$0.011 \mathrm{Pt}+0.02 \mathrm{IPOt}+0.051 \mathrm{VSt}$

(0.06) $\quad(0.34)$

$(0.35)$

$\mathrm{F}=27.1, \bar{R}^{2}=0.93$

Production Equation

QPOt $=1.014-0.204 \mathrm{QIOt}+0.52 \mathrm{QCOt}+0.001 \mathrm{RPOt}+$

0.017 IPOt -0.127 QVOt

$$
(-2.06) * \quad(3.9) * *
$$

(1.49)

$(-1.01)$

$\mathrm{F}=23.7, \bar{R}^{2}=0.88$

Import Equation

QIOt $=7.29+0.566$ QCOt $-1.73 \mathrm{QPOt}+0.551 \mathrm{QVOt}+0.012 \mathrm{RNIt}-$

$(-2.7) *$

$(2.71) *$

0. 002 IPOt -0.106 EXDt-0.008 RPOt

$(-0.72) \quad(-0.26)$

$\mathrm{F}=4.52, \bar{R}^{2}=0.69$ 
local production of wheat in one unit leads to an increase in the quantity consumed by about 0.685 million tons; the correlation coefficient shows that about 93.1\% of the changes in the amount of wheat consumed are due to the effect of the factors mentioned in the model. The calculated $F$ value is about 27.1, which confirms the significance of the model (Ehab 2017).

\section{Factors affecting the domestic production of wheat} The correlation between the quantity of domestic wheat production and the real local price of wheat, the import price, and the quantity of wheat stock was not substantiated. However, the correlation between the quantity of domestic wheat production as a dependent variable and the quantity of wheat consumed did not prove significant as well as the correlation between the quantity of local wheat production and the quantity of domestic consumption of wheat. It was found that increasing the quantity of local wheat production by 1 million tons leads to an increase in the quantity of local consumption of wheat by 0.521 million tons of wheat and the quantity of wheat imports. The significance of the relationship was proved as the decrease in the quantity of imports by 1 million tons of wheat leads to an increase in the quantity of local wheat production by 0.204 million tons, while the relation between the quantity of domestic production of wheat, the local price, the import price of wheat, and the adjusted limiting factor shows that $88 \%$ of the changes in the quantity of domestic production of wheat are attributed to the effect of the factors mentioned in this model. The calculated $F$ value is about 23.7, which confirms the significance of the model.

Factors affecting wheat imports The correlation between the quantity of imports of wheat and the quantity produced from wheat proved to be significant, indicating that the increase in the quantity produced by wheat by 1 million tons leads to a positive correlation between the quantity of wheat imports and the quantity of wheat consumed and the real national income. The decrease in the quantity of imports by 1.738 million tons, as well as the existence of a positive relationship, corresponds to the economic logic between the quantity of imports of wheat and the amount of wheat stock. The statistical significance of the relationship between the quantity of wheat imports and the quantity of wheat stock has been proved; the increase in the population and the consequent increase in the amount of wheat consumed locally together with the increase in the stock of wheat cannot meet the growing demand for wheat, leading to an increase in the quantity of imports of wheat; an inverse relationship consistent with the economic logic between the amount of imports from wheat and the amount of local wheat production was found, and the value of the modified limiting factor indicates that $69 \%$ of the changes in the quantity of imports of wheat are due to the effect of the factors mentioned in the model. The calculated $F$ value is about 4.5, which confirms the significance of the model.

\section{Results of the second phase estimates of the model (reduced image)}

Table 4 shows the reduced image estimates of the model. The results of the reduced image confirmed the estimates of the first stage. The variables were more accurate. The second stage estimate shows the logical and significant parameters estimated at this stage, which reflects the overall changes more accurately. The calculated $F$ value was statistically significant, indicating the significance of the estimated relations in the model at a significant level of 0.05 , which indicates the efficiency of the relations of the denominator in the expression of the relationship between the quantity of wheat imports and the influencing factors as well as the production and consumption equivalents.

Factors affecting the domestic consumption of wheat The statistical significance of the relationship between the quantity of wheat consumed and the number of the population was found to be significant. The increase in the population by 1 million was the result of increasing the quantity of consumed wheat by 0.185 million. The increase in subsidies by 1 billion pounds leads to an increase in the quantity of wheat consumed by 0.059 million tons. The opposite is true in the economic logic between the quantity of consumed wheat and the real local price of wheat and the import price of wheat. A statistical relationship was found between the quantity of wheat consumed and the local real price of wheat. It was found that the increase in the real wheat price of one pound per ton reduces the quantity of consumed wheat by 0.003 million tons. It was found that the increase in the import price of wheat by one dollar per ton reduces the quantity of consumed wheat by 0.002 million tons. It is estimated that $99 \%$ of the changes in wheat consumption are due to the effect of the factors mentioned in this model. The calculated $F$ value that is about 566 confirms the significance of the model.

\section{Factors affecting the domestic production of wheat} The production equation shows the signal agreement with the economic logic. The higher the domestic consumption of wheat by 1 million tons and the domestic price of wheat, the local production of wheat increases by about 0.375 and 0.002 million tons, respectively, while decreasing the import price. Wheat and wheat stock increased the amount of local wheat production by about 0.0005 and 0.149 million tons, respectively. The revised estimation factor shows that $89 \%$ of the changes in the quantity of local wheat production are due to the effect of the factors mentioned in the model. The calculated $F$ 


$$
\begin{aligned}
& \text { Consumption Equation } \\
& \mathbf{Q C O t}=-0.172+0.01 \mathrm{QIOt}+0.059 \mathrm{QPOt}-0.026 \mathrm{RPOt}+0.001 \mathrm{RNIt}+ \\
& (3.74) * \quad(0.26) \\
& (-2.84) * \\
& 0.184 \mathrm{Pt}-0.002 \mathrm{IPOt}+0.06 \mathrm{VSt} \\
& (4.5) * * \\
& \mathrm{~F}=566.4, \bar{R}^{2}=0.98 \\
& (-2.3) * \\
& (2.8) * \\
& \text { Production Equation } \\
& \text { QPOt }=1.83+0.06 \mathrm{QIOt}+0.375 \mathrm{QCOt}+0.002 \mathrm{RPOt} \\
& \text { - 0.0004 IPOt + 0.149 QVOt } \\
& \begin{array}{lll}
(0.74) & (2.78) * & 12.3) *
\end{array} \\
& \mathrm{~F}=26.5, \quad \begin{array}{l}
(-2.23) \\
R
\end{array}=0.89 \\
& \text { QIOt }=4.25+0.097 \mathrm{QCOt}+0.106 \mathrm{QPOt}-0.156 \mathrm{QVOt}+0.005 \mathrm{RNIt}- \\
& (5.8) * * \\
& (2.8) * \\
& \text { (1.3) } \\
& 0.002 \text { IPOt }-0.046 \text { EXDt }-0.001 \text { RPOt } \\
& (-2.8) * \quad(0.92) \\
& \mathrm{F}=137 \quad, \bar{R}^{2}=0.98
\end{aligned}
$$

value is about 26.5, which confirms the significance of the model.

Factors affecting wheat imports The import equation estimates that the decrease in domestic consumption of wheat by 1 million tons, the import price of wheat by one dollar, and the quantity of wheat stock by 1 million tons each lead to an increase in the quantity of imports of wheat at a rate of $0.97,0.002$, and 0.156 million tons, respectively, while the increase in real national income by 1 billion pounds increases the quantity of imports by about 0.005 million tons. The increase in the quantity of wheat imports, despite the increase in local wheat production, indicates that domestic consumption is increasing at a higher rate than the increase in wheat production and population increase, and the value of the modified limiting factor indicates that about $98 \%$ of the changes in the quantity of wheat imports are due to the effect of the factors mentioned in the model. The calculated $F$ value is about 137, which confirms the significance of the model.

It is clear from the above that the most important factors affecting the Egyptian imports of wheat are the amount of domestic consumption, the size of the stock of wheat, the real national income, and the import price of wheat.

\section{Discussion of results}

In conclusion, while the factors affecting Egyptian imports of wheat remain the same, the probability of an increase in the Egyptian import bill increases year after year with a consequent increase in the deficit of the Egyptian trade balance, as well as of the agricultural trade balance, raising the percentage of self-sufficiency of wheat whether by encouraging horizontal expansion by increasing the cultivated area of strategic crops such as wheat, especially in newly reclaimed lands such as the 1 million and a half feddan land, or vertical expansion by increasing the productivity of feddan through supporting agricultural research and activating the role of agricultural extension, or both.

\section{Conclusions}

To study the factors that affect the production, consumption, and imports in order to narrow the gap between production and consumption so as not to negatively affect the rates of development in Egypt, and alleviate the deficit of the Egyptian trade balance, the average consumption was 16.6 million tons while the production amounted to about 9.3 million tons and 7.3 million tons, and support for wheat and flour is estimated at 13.7 billion Egyptian pounds during the period 2012-2016. 
The problem of research is that Egypt faces a population increase of about 2.6 million people annually, and despite the increase in production of wheat, the corresponding increase in consumption is increasing at a higher rate, leading to an increase in Egyptian imports, which is a burden on Egypt's agricultural trade balance. The analysis of the structure of Egyptian foreign trade for wheat is aimed at identifying the most important economic factors affecting the production, consumption, and imports of wheat by constructing a standard model for analyzing the foreign wheat trade market.

The research was based on descriptive and quantitative analysis using various measures such as relative importance and averages. Simple regression analysis was used. Simultaneous Equation System was also used to design a standard model for analyzing the structure of Egyptian wheat imports. Using the equation of consumption and the most important factors and the equation of production and the equation of imports and factors and then an identification equation and the study found that the best way to estimate in this case is the two-step (2SLS) two squares method, which gives more efficient estimates.

The research was based mainly on statistical data published and unpublished from several sources such as the Ministry of Agriculture and the Central Agency for Public Mobilization and Statistics.

The study concluded that while the factors affecting Egyptian imports of wheat remain the same, the probability of an increase in the Egyptian import bill increases year after year with a consequent increase in the deficit of the Egyptian trade balance, as well as of the agricultural trade balance, raising the self-sufficiency ratio of wheat whether by encouraging horizontal expansion by increasing the cultivated area of strategic crops such as wheat, especially in the newly reclaimed lands such as the 1 million and a half feddan lands, or vertical expansion by increasing the productivity of the feddan through supporting agricultural research and activating the role of wheat and agricultural guidance, or following both methods.

\section{Acknowledgements}

The authors would like to extend their sincere thanks and appreciation to all the staff of Central Agency for Public Mobilization and Statistics and the staff of Economic Affairs Sector Ministry of Agriculture and Land Reclamation for their assistance in carrying out this study.

\section{Authors' contributions}

YMMK wrote the research paper (research design, scientific background writing, presentation, and interpretation of results). TGIM collected the secondary data. SSAel-G did the statistical analysis of data. All authors read and approved the final manuscript.

\section{Authors' information}

Prof. Yehia Mohamed Metwally Khalil. Professor at Agricultural Economics Department, National Research Center.

Dr. Tamer Gamal Ibrahim Mansour. Researcher at the National Research Center.
Dr. Salah Said Abd el- Ghani. Assistant Professor, Department of Economics, Faculty of Economics and Administrative Sciences, Imam Muhammad ibn Saud Islamic University - Saudi Arabia.

Funding

There is no funding for this study.

\section{Availability of data and materials}

Materials described in the manuscript, including all relevant raw data, will be freely available to any scientist wishing to use them for non-commercial purposes.

Ethics approval and consent to participate

Not applicable.

\section{Consent for publication}

Not applicable.

\section{Competing interests}

The authors declare that they have no competing interests.

\section{Author details}

${ }^{1}$ Department of Agricultural Economics, Division of Agricultural and Biological Research, National Research Center, El Buhouth St., Dokki, Giza 12622, Egypt. ${ }^{2}$ Department of Economics, Faculty of Economics and Administrative Sciences, Imam Muhammad ibn Saud Islamic University, Riyadh, Saudi Arabia.

Received: 10 July 2018 Accepted: 20 January 2020

Published online: 05 February 2020

\section{References}

Abdelkader AM (2000) Modern in the econometrics between theory and practice. University House, Alexandria

Ahmed MA-M (2017) An economic study of the factors affecting the foreign trade of some Egyptian food oils. Department of Agricultural Economics, Faculty of Agriculture, Cairo University

Central Agency for Public Mobilization and Statistics, Statistical Yearbook, different years (n.d.). https://www.capmas.gov.eg/Pages/StaticPages. aspx?page_id=5034

Ehab Merid, Shrein Michael (Doctor) Economic study of the most important grain crops in Egypt using the model of partial balance, the Egyptian Journal of Agricultural Economics, Volume XXVII, the first issue in March 2017

Ministry of Agriculture and Land Reclamation, Economic Affairs Sector, Agricultural Economics Bulletin, different years n.d. Available at http://www agr-egypt.gov.eg

The Central Agency for Public Mobilization and Statistics (CAPMAS), Annual Bulletin of Foreign Trade, different years n.d. Available athttps://www.capmas. gov.eg/Pages/Publications.aspx?page_id=5107\&YearlD=23320

\section{Publisher's Note}

Springer Nature remains neutral with regard to jurisdictional claims in published maps and institutional affiliations.

\section{Submit your manuscript to a SpringerOpen ${ }^{\circ}$ journal and benefit from:}

- Convenient online submission

- Rigorous peer review

- Open access: articles freely available online

- High visibility within the field

- Retaining the copyright to your article

Submit your next manuscript at $>$ springeropen.com 